\title{
Germination changes the isoflavone profile and increases the antioxidant potential of soybean
}

\author{
Luciane Yuri Yoshiara ${ }^{\mathrm{a}}$, José Marcos Gontijo Mandarino ${ }^{\mathrm{b}}$, Mercedes Concórdia Carrão-Panizzic, \\ Tiago Bervelieri Madeira ${ }^{a}$, Josemeyre Bonifácio da Silva ${ }^{\mathrm{a}}$, Adriano Costa de Camargo ${ }^{\mathrm{a}, \mathrm{d}}$, \\ Fereidoon Shahidi ${ }^{\mathrm{d}}$ and Elza Iouko Ida ${ }^{\mathrm{a}^{*}}$
}

\begin{abstract}
aUniversidade Estadual de Londrina, Departamento de Ciência e Tecnologia de Alimentos, Campus Universitário, Caixa Postal 10.011, CEP 86057-970, Londrina, Paraná, Brazil

bEmbrapa Soja, Rodovia Carlos João Strass, Acesso Orlando Amaral, Distrito Warta, Caixa Postal 231, CEP 86001-970, Londrina, Paraná, Brazil

${ }^{c}$ Embrapa Trigo, Rodovia BR-285, Km 294, Caixa Postal 451, CEP 99001-970, Passo Fundo, Rio Grande do Sul, Brazil

dDepartment of Biochemistry, Memorial University of Newfoundland, St. John's, NL A1B 3X9, Canada

*Corresponding author: Elza Iouko Ida, Universidade Estadual de Londrina, Departamento de Ciência e Tecnologia de Alimentos, Campus Universitário, Caixa Postal 10.011, CEP 86057-970, Londrina, Paraná, Brazil. Tel: +55 43 33714080; Fax: +55 43 33714080; E-mail: elida@uel.br
\end{abstract}

DOI: $10.31665 / J F B .2018 .3157$

Received: August 02, 2018; Revised received \& accepted: August 26, 2018

Citation: Yoshiara, L.Y, Mandarino, J.M.G, Carrão-Panizzi, M.C., Madeira, T.B, da Silva, J.B., de Camargo, A.C, Shahidi, F., and Ida, E.I. (2018). Germination changes the isoflavone profile and increases the antioxidant potential of soybean. J. Food Bioact. 3: 144-150.

\begin{abstract}
Isoflavones, which exist in their conjugated or aglycone forms, are well recognized for their potential health benefits. However, isoflavones as aglycone have been regarded as the most bioactive form. In the present study, the profile of isoflavones and their scavenging activity as affected by germination were investigated in several soybean fractions, namely cotyledons, epicotyls, radicles, and hypocotyls. Only aglycones were detected in the radicles from $144 \mathrm{~h}$ until $168 \mathrm{~h}$ of germination, which makes this component a potential feedstock for studies aiming at isolation, especially of daidzein, which was present in higher concentrations. In terms of total yield and contribution to the total weight of the germinated soybeans, the cotyledons are the best source of aglycones, which was achieved at $144 \mathrm{~h}$ of germination. The higher scavenging activity of high-aglycone components from germinated soybeans supports the use of germination to obtain functional foods and/or ingredients with potentially superior bioactivities.
\end{abstract}

Keywords: Germinated soybeans; Phenolic compounds; $\beta$-glycoside isoflavone; Malonyglucoside isoflavones; Isoflavone aglycones; Antiradical activity.

\section{Introduction}

There are 12 different isoflavones, three conjugated groups $[\beta$-glycosides (e.g., daidzin, genistin and glycitin), acetylglycosides (e.g., acetyldaidzin, acetylgenistin and acetylglycitin) and malonylglycosides compounds (e.g., malonyldaidzin, malonylgenistin and malonylglycitin)] present in soybeans; the latter representing the aglycones (e.g., daidzein, genistein and glycitein) which do not have any glucose moiety linked to the flavonoid structure (Falcão et al., 2018). During soybean seed development in the field, aglycones are synthesized by the phenylpropanoid metabolic pathway and are further stored in vacuoles as $\beta$-glucosides and malonylglucosides (Graham, 1991; Kudou et al., 1991). The concentration of isoflavones in soybean seeds may vary because their synthesis and accumulation pathways are affected by multiple environmental variations and genetic factors (Hoeck et al., 2000). Regardless, conjugated isoflavones present in soybeans make a higher contribution when compared to their aglycone 
counterparts (Kudou et al., 1991). In a study by Quinhone Júnior and Ida (2015), the content of conjugated isoflavones ( $\beta$-glucoside plus malonylglucoside form) accounted for $99 \%$ of the isoflavones present, while the remaining $1 \%$ as aglycones made a minor contribution. Furthermore, isoflavones in the acetylglucoside form are generally absent in soybeans or are present at very low concentrations (Paucar-Menacho et al., 2010). Isoflavones have been found to be absent or make an insignificant contribution to the phenolic content of the soybean seed coat (Kudou et al., 1991; Ribeiro et al., 2006; Yuan et al., 2009), thus demonstrating that the distribution and the identities of phenolics are tissue specific.

Germination may increase the nutritional value of the seed while reducing the amount of undesirable substances such as flatulence-inducing components and antinutrients (Kim et al., 2013; Martín-Cabrejas et al., 2008; Paucar-Menacho et al., 2010). Bioactive compounds such as phytosterols, tocopherols, and flavonoids have also been found to be positively affected by germination (Lee et al., 2007; Paucar-Menacho et al., 2010; Shi et al., 2010; Yuan et al., 2009). Furthermore, soybean germination activates $\beta$-glucosidases thus causing changes in the concentration as well as in the structural pattern of isoflavones (Yoshiara et al. 2018; Ribeiro, et al., 2006). Soybean sprouts have already been investigated as potential feedstocks in the development of soymilk and tofu (Murugkar, 2015).

Although several studies have supported the conversion of conjugated isoflavones into their aglycone counterparts during soybean germination (Quinhone Júnior and Ida, 2015), there are still some apparent gaps in the literature, especially when it comes to the effects of such a process in the potential bioactivity of soybean sprouts and, in turn, their industrial products, which may enhance the knowledge of the soybean industry in developing functional foods. Furthermore, most studies focusing on germination have evaluated the changes in their individual bioactives in homogenized samples, ignoring the fact that different phenolics may be synthetized in specific parts of the plant. Finally, the consumption of germinated soybeans is more common in Japan, and China, but the market still has a great potential to grow in other countries such as Brazil, Canada, and United States. Likewise, Europe could be a great market for germinated soybeans as Europeans are also willing to consume healthier foods. However, the lack or scarcity of information on the effects of germination in such a product may jeopardize their popularization. Thus, the aim of this study was to evaluate the concentration of different forms of isoflavones in several parts of germinated soybeans, namely radicles, hypocotyls, epicotyls and cotyledon. The scavenging activity of isoflavones extracted from each part has also been investigated and the results are discussed in terms of structure and/or potential bioactivities.

\section{Material and methods}

\subsection{Materials and chemicals}

Soybean seeds (Glycine $\max$ (L.) Merrill), cv. BRS 257, were kindly provided by Embrapa Soja, Londrina, Paraná state, Brazil. All reagents were of analytical or HPLC grade and were used as received.

\subsection{Germination process of soybean}

The germination process was conducted as described elsewhere (Yoshiara et al., 2011). At each germination time (72, 96, 120, 144 and $168 \mathrm{~h}$ ), radicles, hypocotyls, cotyledons and epicotyls were manually separated and freeze dried while the coats were discarded. The radicle and epicotyls began to germinate after $72 \mathrm{~h}$. All germinated soybean components were ground and stored at -22 ${ }^{\circ} \mathrm{C}$ for further analysis. For comparison purposes, non-germinated soybeans, which were lyophilized, milled, and defatted, were used.

\subsection{Extraction of phenolic compounds}

Phenolic extraction was conducted with $70 \%$ ethanol containing $0.1 \%$ acetic acid. In brief, defatted soybeans $(100 \mathrm{mg})$ were extracted with acidified ethanol $(4.0 \mathrm{~mL})$ in a RT 500 gyratory shaker (Marconi, Piracicaba, Brazil) for $20 \mathrm{~min}$. After centrifugation at $2000 \times g$ (Cientec-Piracicaba, Brazil), the upper layer was collected and extraction was repeated twice. The combined supernatant was evaporated to remove the organic solvent and then stored at $-26^{\circ} \mathrm{C}$ until used for further analyses.

\subsection{Identification and quantification of isoflavones by high per- formance liquid chromatography (HPLC)}

The HPLC instrument (Shimadzu, LC-10AT VP, Kyoto, Japan) coupled to a diode array detector (SPD-M10A VP) set at $260 \mathrm{~nm}$ was employed for identification and quantification purposes. The oven (CTO-10AS VP) temperature was kept constant $\left(25^{\circ} \mathrm{C}\right)$. Phenolic extracts were filtered through nylon membranes $(0.20$ $\mu \mathrm{m})$ and injected $(20 \mu \mathrm{L})$ in a reversed-phase ODS (M) C18 column $(15 \mathrm{~cm} \times 4 \mathrm{~mm} \times 5 \mu \mathrm{m})$. Acidified water, prepared with glacial acetic acid ( $\mathrm{pH}$ 3.0), was the mobile phase A and the mobile phase $\mathrm{B}$ consisted of acetonitrile. The elution gradient used was as follows; $0 \mathrm{~min}, 100 \% \mathrm{~A} ; 25 \mathrm{~min}, 45 \% \mathrm{~A}$; and $27 \mathrm{~min}, 100 \% \mathrm{~B}$. The initial condition was re-established at $40 \mathrm{~min}$. The total run took $40 \mathrm{~min}$ and the flow rate was $1 \mathrm{~mL} \mathrm{~min}{ }^{-1}$. The identification and quantification of the $\beta$-glycosides and aglycone isoflavones were performed by using external standard curves for daidzin, glycitin, genistin, daidzein, glycitein and genistein. The quantification of malonylglycoside isoflavones (e.g., malonyldaidzin, malonylglycitin and malonylgenistin) was made based on the standard curves of the corresponding $\beta$-glycosides isoflavones (i.e., daidzin, glycitin and genistin, respectively) using the similarity of the molar extinction coefficients as described by Coward et al. (1993). The concentrations are expressed as mg of isoflavone $100 \mathrm{~g}^{-1}$ dry weight of sample.

\subsection{Total phenolic content (TPC)}

The Folin-Ciocalteau method (Swain and Hillis, 1959), described by de Camargo et al. (2015), was slightly modified to estimate the TPC. Phenolic extracts $(0.50 \mathrm{~mL}), 2.5 \mathrm{~mL}$ of a diluted solution of phenol reagent $(10 \%)$ and $2.0 \mathrm{~mL}$ of sodium carbonate saturated solution $(7.5 \%, \mathrm{~m} / \mathrm{v})$ were mixed thoroughly and incubated in a water bath at $50{ }^{\circ} \mathrm{C}$ for $5 \mathrm{~min}$. The absorbance was read at $760 \mathrm{~nm}$ using a spectrophotometer (Biochrom Libra S22, Cambridge, England). The results were expressed as mg gallic acid equivalents 100 $\mathrm{g}^{-1}$ dry weight of defatted sample.

\subsection{DPPH radical scavenging activity}

The ability of the phenolic extracts in scavenging DPPH radical was evaluated according to Brand-Williams et al. (1995). The ex- 
Table 1. Content of different forms of isoflavones $\left(\mathrm{mg} 100 \mathrm{~g}^{-1} \mathrm{dw}\right)$ of germinated soybeans

\begin{tabular}{|c|c|c|c|c|c|}
\hline Soybean component & Time (h) & $\beta$-glycosides & Malonyl & Aglycone & Total \\
\hline \multirow[t]{6}{*}{ Cotyledons } & 0 & $66.73 \pm 0.67^{b}$ & $287.20 \pm 2.08^{\mathrm{d}, \mathrm{e}}$ & $2.24 \pm 0.03^{m}$ & $356.17 \pm 2.78^{e}$ \\
\hline & 72 & $23.74 \pm 0.57^{c, d}$ & $377.02 \pm 2.26^{c}$ & $35.89 \pm 0.28^{\mathrm{i}, \mathrm{j}, \mathrm{k}}$ & $436.25 \pm 2.54 c, d, e$ \\
\hline & 96 & $34.38 \pm 0.20^{b, c, d}$ & $284.02 \pm 1.00^{\mathrm{d}, \mathrm{e}}$ & $70.26 \pm 0.61^{d}$ & $388.65 \pm 0.59^{d, e}$ \\
\hline & 120 & $24.11 \pm 0.11^{c, d}$ & $288.86 \pm 0.27^{d}$ & $89.40 \pm 0.51^{c}$ & $402.37 \pm 0.13^{\mathrm{d}, \mathrm{e}}$ \\
\hline & 144 & $14.70 \pm 0.44^{d}$ & nd & $149.61 \pm 2.04^{\mathrm{a}}$ & $164.31 \pm 2.48^{f, g, h}$ \\
\hline & 168 & $47.75 \pm 0.14^{b, c, d}$ & $498.02 \pm 0.26^{a, b}$ & $67.81 \pm 0.42^{d}$ & $613.59 \pm 0.82^{b}$ \\
\hline \multirow[t]{3}{*}{ Epicotyls } & 120 & nd & nd & $34.75 \pm 0.20^{\mathrm{j}, \mathrm{k}}$ & $34.75 \pm 0.20^{h}$ \\
\hline & 144 & $16.43 \pm 2.71^{d}$ & $161.07 \pm 3.49^{f}$ & $34.22 \pm 0.43^{k, l}$ & $211.71 \pm 5.77^{\mathrm{f}, \mathrm{g}}$ \\
\hline & 168 & $18.72 \pm 0.33^{d}$ & $138.97 \pm 4.09^{f}$ & $95.66 \pm 0.61^{b}$ & $253.35 \pm 3.80^{f}$ \\
\hline \multirow[t]{5}{*}{ Radicles } & 72 & $66.97 \pm 2.32^{b}$ & $435.13 \pm 3.89^{a, b}$ & $55.26 \pm 1.72^{\mathrm{e}}$ & $557.36 \pm 7.92^{b, c}$ \\
\hline & 96 & $61.34 \pm 0.96^{b, c}$ & $406.72 \pm 6.33^{b}$ & $51.44 \pm 0.58^{e, f}$ & $519.51 \pm 7.87^{b, c, d}$ \\
\hline & 120 & $61.33 \pm 0.93^{b, c}$ & $450.03 \pm 7.55^{b, c}$ & $47.65 \pm 0.61^{\mathrm{f}, \mathrm{g}}$ & $559.00 \pm 7.87^{b, c}$ \\
\hline & 144 & nd & nd & $41.49 \pm 0.13^{g, h, i}$ & $41.49 \pm 0.13^{h}$ \\
\hline & 168 & nd & nd & $40.47 \pm 0.04^{h, i, j}$ & $40.47 \pm 0.04^{h}$ \\
\hline \multirow[t]{6}{*}{ Hypocotyls } & 0 & $656.95 \pm 43.54^{\mathrm{a}}$ & $1635.31 \pm 90.05^{a}$ & $38.32 \pm 1.99^{h, \mathrm{i}, \mathrm{j}, \mathrm{k}}$ & $2330.58 \pm 135.59^{a}$ \\
\hline & 72 & $46.21 \pm 0.74^{b, c, d}$ & $206.68 \pm 2.72^{e, f}$ & $153.32 \pm 5.26^{a}$ & $406.20 \pm 8.72^{\mathrm{d}, \mathrm{e}}$ \\
\hline & 96 & $18.49 \pm 0.41^{d}$ & $11.88 \pm 0.29 \mathrm{~g}$ & $83.66 \pm 0.73^{c}$ & $114.03 \pm 0.04^{g, h}$ \\
\hline & 120 & $8.36 \pm 0.07^{d}$ & $22.22 \pm 0.50^{g}$ & $28.23 \pm 1.09^{\mid}$ & $58.82 \pm 0.52^{h}$ \\
\hline & 144 & nd & nd & $42.80 \pm 0.85^{g, h}$ & $42.80 \pm 0.85^{h}$ \\
\hline & 168 & $20.20 \pm 0.20^{d}$ & nd & $55.12 \pm 1.77^{e}$ & $75.32 \pm 1.97^{h}$ \\
\hline
\end{tabular}

Data represent mean values \pm standard deviation $(n=3)$. Values followed by the same letters within a column are not significantly different $(p>0.05)$. nd, not detected.

tracts $(50 \mu \mathrm{L})$ were mixed with $1 \mathrm{~mL}$ of acetate buffer $(0.1 \mathrm{M}, \mathrm{pH}$ $5.5), 1 \mathrm{~mL}$ of ethanol and $0.5 \mathrm{~mL}$ of DPPH solution $(250 \mu \mathrm{M})$. After 30 min standing in the dark, the absorbance was read 517 $\mathrm{nm}$ using a spectrophotometer (Biochrom Libra S22, Cambridge, England). The DPPH radical scavenging activity of the extracts was calculated using the following equation.

DPPH radical scavenging activity $(\%)=\left(\mathrm{Abs}_{\text {control }}-\mathrm{Abs}_{\text {sample }}\right) /$ $\left.\left(\mathrm{Abs}_{\text {control }}\right)\right] \times 100$

where $\mathrm{Abs}_{\text {control }}$ is the absorbance of DPPH radical + ethanol; and $\mathrm{Abs}_{\text {sample }}$ the absorbance of DPPH radical + phenolic extract or trolox. The results were expressed as $\mu \mathrm{mol}$ of trolox equivalents $\mathrm{g}^{-1}$ dry weight of sample.

\subsection{ABTS radical cation scavenging activity}

The ABTS assay (Re et al., 1999) was performed with minor changes in the method described by de Camargo et al (2015). The ABTS radical cation, prepared in $100 \mathrm{mM}$ phosphate buffer saline (PBS) solution ( $\mathrm{pH} 7.4,0.15 \mathrm{M}$ sodium chloride), was generated by oxidation with potassium persulphate. The stock solution consisted of potassium persulphate $(2.45 \mathrm{mM})$ and ABTS $(7 \mathrm{mM})$ in PBS. The oxidation was conducted in the dark for $16 \mathrm{~h}$. A working solution of ABTS radical cation was prepared by diluting the stock solution in PBS to reach an absorbance value of $0.700 \pm$ 0.020 at $730 \mathrm{~nm}$. Phenolic extracts $(10 \mu \mathrm{L})$ were added to $4 \mathrm{~mL}$ of ABTS radical cation solution and the absorbance was read at
$730 \mathrm{~nm}$ after 6 min using a spectrophotometer (Biochrom Libra S22, Cambridge, England). ABTS radical scavenging activity was calculated using the following equation.

ABTS radical scavenging activity $(\%)=\left[\left(\mathrm{Abs}_{\text {control }}-\mathrm{Abs}_{\text {sample }}\right) /\right.$ $\left.\left(\mathrm{Abs}_{\text {control }}\right)\right] \times 100$

where $\mathrm{Abs}_{\text {control }}$ is the absorbance of ABTS radical cation + ethanol; and $\mathrm{Abs}_{\text {sample }}$ the absorbance of ABTS radical cation + phenolic extract or trolox. The results were expressed as $\mu \mathrm{mol}$ of trolox equivalents $\mathrm{g}^{-1}$ dry weight of sample.

\subsection{Experimental design and statistical analysis}

A randomized complete block design with three replications was used. The means were compared by Tukey's test $(p<0.05)$ and Statistica 8.0 software (StatSoft Inc., Tulsa, OK, USA).

\section{Results and discussion}

\subsection{Germination-induced changes of isoflavones}

The amounts of different isoflavone forms from cotyledons, epicotyls, radicles and hypocotyls of germinated soybeans are shown in Table 1. Irrespective of the germination period, acetylglycoside isoflavones were absent in all components of the test material, 
Table 2. Total isoflavone concentration and contribution of conjugated and aglycone isoflavones of different germinated soybean components

\begin{tabular}{|c|c|c|c|c|c|}
\hline GT (h) & & Radicles & Hypocotyls & Epicotyls & Cotyledons \\
\hline \multirow[t]{3}{*}{0} & Total (mg $100 \mathrm{~g}^{-1} \mathrm{dw}$ ) & $*$ & $2330.58 \pm 135.59 \mathrm{~A}^{\mathrm{a}}$ & $*$ & $356.17 \pm 2.78 \mathrm{~B}^{\mathrm{e}}$ \\
\hline & Conjugated (\%) & $*$ & 98.36 & $*$ & 99.37 \\
\hline & Aglycones (\%) & $*$ & 1.64 & $*$ & 0.63 \\
\hline \multirow[t]{3}{*}{72} & Total (mg $100 \mathrm{~g}^{-1} \mathrm{dw}$ ) & $557.36 \pm 7.92 \mathrm{~A}^{\mathrm{a}}$ & $406.20 \pm 8.72 C^{b}$ & nd & $436.25 \pm 2.54 \mathrm{~B}^{\mathrm{b}}$ \\
\hline & Conjugated (\%) & 90.09 & 62.26 & nd & 91.78 \\
\hline & Aglycones (\%) & 9.91 & 37.74 & nd & 8.22 \\
\hline \multirow[t]{3}{*}{96} & Total (mg $\left.100 \mathrm{~g}^{-1} \mathrm{dw}\right)$ & $519.51 \pm 7.87 \mathrm{~A}^{\mathrm{b}}$ & $114.03 \pm 0.04 C^{c}$ & nd & $388.65 \pm 0.59 B^{d}$ \\
\hline & Conjugated (\%) & 90.10 & 25.75 & nd & 81.92 \\
\hline & Aglycones (\%) & 9.90 & 74.25 & nd & 18.08 \\
\hline \multirow[t]{3}{*}{120} & Total (mg $100 \mathrm{~g}^{-1} \mathrm{dw}$ ) & $559.00 \pm 7.87 \mathrm{~A}^{\mathrm{a}}$ & $58.82 \pm 0.52 C^{c}$ & $34.75 \pm 0.20 D^{c}$ & $402.37 \pm 0.13 \mathrm{~B}^{\mathrm{C}}$ \\
\hline & Conjugated (\%) & 91.48 & 52.00 & 0.00 & 77.78 \\
\hline & Aglycones (\%) & 8.52 & 48.00 & 100.00 & 22.22 \\
\hline \multirow[t]{3}{*}{144} & Total (mg $\left.100 \mathrm{~g}^{-1} \mathrm{dw}\right)$ & $41.49 \pm 0.13 C^{c}$ & $42.80 \pm 0.85 C^{c}$ & $211.7 \pm 5.77 A^{b}$ & $164.31 \pm 2.48 B^{f}$ \\
\hline & Conjugated (\%) & 0.00 & 0.00 & 83.84 & 8.95 \\
\hline & Aglycones (\%) & 100.00 & 100.00 & 16.16 & 91.05 \\
\hline \multirow[t]{3}{*}{168} & Total (mg $\left.100 \mathrm{~g}^{-1} \mathrm{dw}\right)$ & $40.47 \pm 0.04 D^{c}$ & $75.32 \pm 1.97 C^{c}$ & $253.35 \pm 3.80 \mathrm{~B}^{\mathrm{a}}$ & $613.59 \pm 0.82 A^{a}$ \\
\hline & Conjugated (\%) & 0.00 & 26.82 & 62.24 & 88.95 \\
\hline & Aglycones (\%) & 100.00 & 73.18 & 37.76 & 11.05 \\
\hline
\end{tabular}

*The radicles and epicotyls were absent at time zero. Total isoflavone represent mean values \pm standard deviation $(n=3)$. Values followed by different capital letters within a row show differences among different germinated soybean components $(p<0.05)$. Values followed by different lowercase letters within a column show differences among different germination times $(p<0.05)$. Abbreviations: GT, germination time; and nd, not detected.

which was expected since acetylglycoside isoflavones are generated upon heating treatment (Kudou et al., 1991). This is also in agreement with a previous study (Falcão et al., 2018) in which these isoflavone forms were not detected. The concentration of total isoflavones in hypocotyls of non-germinated soybeans was higher than that of cotyledons, while the remaining soybean components, namely epicotyls and radicles, only appeared during the germination process. Regardless of the germination time, cotyledons made the highest contribution to the total weight of the germinated soybeans (Yoshiara et al., 2011). According to the aforementioned study, at the latest stages of germination, the contribution of each fraction was in the order cotyledons $>$ hypocotyls $>$ radicle $>$ epicotyl, and the latter one made only a minor contribution, ranging from 0.4 to $2.3 \%$. The variation in the concentration of different isoflavone forms is helpful to better understand the biochemistry involved in the germination process. However, in terms of application in functional foods and/or functional ingredients, the changes taking place in the cotyledon are most important. The concentration of aglycones in the cotyledon increased up to $144 \mathrm{~h}$ of germination (Table 1), after which a decrease was noted. Because of their higher number of hydroxyl groups, the aglycones may act better as antioxidants. Therefore, such decreasing trend may be related to the oxidation of these phenolic antioxidants. In general, hypocotyls from germinated soybeans also showed higher amounts of aglycones compared to their non-germinated counterparts. The radicles and epicotyls started to develop later and, at $72 \mathrm{~h}$ of germination, $9.9 \%$ of the isoflavones present in the radicles were in the aglycone form (Table 2). However, at the end of the germination period, only aglycones were detected in this part of the plant material.

In general, the higher yield of isoflavones in the aglycone form was detected at $144 \mathrm{~h}$ of germination: $100 \%$ for radicles and hypocotyls and $91.05 \%$ for cotyledon, except the epicotyls, that presented only $16.2 \%$ of aglycones. However, as mentioned earlier, the epicotyls make a minor contribution to the weight of the germinated soybean (Yoshiara et al., 2011). Therefore, $144 \mathrm{~h}$ of germinaiton appears to be the best time to obtain high-aglycone soybean feedstocks (Table 2), for which a total characterization of the isoflavones was undertaken (Table 3). Malonylgenistin and daidzin were the predominant malonylglycoside and $\beta$-glycosides isoflavones in non-germinated soybeans, respectively, while no significant differences were found between both aglycones (daidzein and genistein) detected. The concentration of both was minor

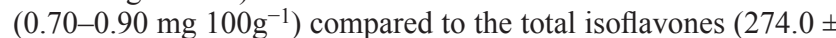
$\left.0.10 \mathrm{mg} 100 \mathrm{~g}^{-1}\right)$. Furthermore, glycitein was not detected in nongerminated soybeans, which is in accordance with a recent report by Falcão et al. (2018). Soybean components subjected to $144 \mathrm{~h}$ of germination (Table 3 ) showed the following levels of total isoflavones: epicotyl $\left(211.7 \pm 4.08 \mathrm{mg} 100 \mathrm{~g}^{-1}\right)$, cotyledon $(164.31 \pm$

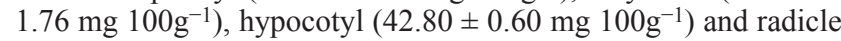
$\left(41.49 \pm 0.09 \mathrm{mg} .100 \mathrm{~g}^{-1}\right)$ and any presence of conjugated isoflavones was detected in hypocotyl and radicle. Furthermore, different from hypocotyls, the amount of total isoflavones was quite constant in the radicle, which showed $100 \%$ aglycones until the end of the germination period (Table 2), thus making this component the best feedstock for studies aiming at isolation, especially of daidzein, which was present in higher concentrations.

Germinated soybean epicotyl was the only component that contained all three aglycone forms. Glycitin, which was present in non-germinated soybeans, was not detected in the germinated samples. In contrast, the aglycone glycitein was detected only 
Table 3. The contents of isoflavones ( $\mathrm{mg} 100 \mathrm{~g}^{-1} \mathrm{dw}$ ) of non-germinated soybean and samples germinated for $144 \mathrm{~h}$ at $35{ }^{\circ} \mathrm{C}$ in the presence of light

\begin{tabular}{|c|c|c|c|c|c|}
\hline \multirow{2}{*}{ Compound } & \multirow{2}{*}{ NGS } & \multicolumn{4}{|c|}{ Germinated soybean components } \\
\hline & & Cotyledons & Epicotyls & Hypocotyls & Radicles \\
\hline Daidzein & $0.90 \pm 0.03^{f}$ & $89.32 \pm 0.89^{a}$ & $15.56 \pm 0.12^{\mathrm{c}}$ & $33.11 \pm 0.41^{\mathrm{a}}$ & $35.71 \pm 0.06^{a}$ \\
\hline Glycitein & nd & nd & $12.94 \pm 0.44^{d}$ & nd & nd \\
\hline Genistein & $0.72 \pm 0.1^{f}$ & $60.28 \pm 0.56^{b}$ & $5.73 \pm 0.01^{f}$ & $9.69 \pm 0.20^{b}$ & $5.78 \pm 0.03^{b}$ \\
\hline Daidzin & $27.04 \pm 0.32^{\mathrm{c}}$ & nd & $8.59 \pm 0.01^{\mathrm{e}}$ & nd & nd \\
\hline Glycitin & $8.61 \pm 0.17^{e}$ & nd & nd & nd & nd \\
\hline Genistin & $21.32 \pm 0.22^{d}$ & $14.70 \pm 0.31^{c}$ & $7.83 \pm 1.93^{e, f}$ & nd & nd \\
\hline Malonyldaidzin & $77.04 \pm 0.85^{b}$ & nd & $69.69 \pm 0.00^{b}$ & nd & nd \\
\hline Malonylglycitin & $21.88 \pm 0.14^{d}$ & nd & $2.79 \pm 0.16^{g}$ & nd & nd \\
\hline Malonylgenistin & $116.5 \pm 0.03^{a}$ & nd & $88.59 \pm 2.31^{\mathrm{a}}$ & nd & nd \\
\hline Total & $274.1 \pm 0.10$ & $164.3 \pm 1.76$ & $211.7 \pm 4.08$ & $42.80 \pm 0.60$ & $41.49 \pm 0.09$ \\
\hline
\end{tabular}

Data represent mean values \pm standard deviation $(n=3)$. Values followed by the same letters within a column are not significantly different $(p>0.05)$. Abbreviations: NGS, nongerminated soybeans; and nd, not detected. Acetyldaidzin, acetylglycitin, and acetylgenistin were absent in all samples.

in epicotyls of germinated soybeans. According to Falcão et al. (2018), no evidence exists for hydrolysis of conjugates of glycitein upon ultrasound treatment (up to $25 \mathrm{~min}$ ). A low specificity of the endogenous $\beta$-glucosidase towards glycitin and malonylglycitin has been reported (Ismael and Hayes, 2005). However, the decrease in the concentration of conjugated isoflavones (glycitin and malonylglycitin) with a parallel increase in their corresponding aglycone (glycitein) upon germination may be related to the action of $\beta$-glucosidase which catalyzes the hydrolysis of conjugated isoflavones, thus generating their respective aglycones. Such differences may be related to several parameters such as enzyme concentration, temperature, and $\mathrm{pH}$ of the medium (Yoshiara et al., 2018). Enzyme activity induced changes upon germination have also been reported by other authors (Wanasundara et al., 1999). Furthermore, the presence of insoluble-bound glycitin has also been reported for soybeans (Peng et al., 2017). According to Yeo and Shahidi (2015), the changes induced by germination are not limited to soluble phenolics as those linked to the cell wall of plant material (insoluble-bound phenolics) have also been affected.

Isoflavones have been associated with disease risk reduction or prevention of various ailments, such as breast cancer and prostate cancer (Liggins et al., 2000), osteoporosis, menopause symptoms (Levis et al., 2010), cardiovascular disease (Liu et al., 2017; Rimbach et al., 2008), memory improvement (Lephart et al., 2002), as well as estrogenic and antioxidant activity (Ma et al., 2010). Isoflavones may also inhibit adipogenesis and lipogenesis via interaction with several transcription factors and upstream signaling molecules (Wang et al., 2017), therefore, may render potential anti-obesity effects. Furthermore, according to a meta-analysis, consumption of dietary flavonoids is associated with a reduced risk of type 2 diabetes (Liu et al., 2014). Soybean aglycones are most biologically active forms under physiological conditions and have been regarded as the best form for absorption in the human body (Falcão et al., 2018). This contribution supports the use of germination as an alternate process to promote the bioconversion of conjugated isoflavones into their corresponding aglycones. Finally, the results presented here (Table 3 ) demonstrate that germinated soybean cotyledons constitute a rich source of aglycones as their concentration of $149.6 \mathrm{mg} 100 \mathrm{~g}^{-1}$ is much higher than that

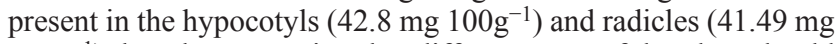
$100 \mathrm{~g}^{-1}$ ) thus demonstrating that different parts of the plant should be evaluated when germination is carried out.

\subsection{Total phenolic content (TPC)}

The TPC of germinated and non-germinated soybeans is presented in Figure 1. The various components of germinated and non-germinated soybean differed from each other $(p<0.05)$. The cotyledon $\left(570.88 \pm 28.80 \mathrm{GAE} 100 \mathrm{~g}^{-1}\right.$ dry weight of sample) showed the highest TPC, which was followed by radicle (398.43 $\pm 18.77 \mathrm{GAE}$ $100 \mathrm{~g}^{-1}$ dry weight of sample), hypocotyl (227.93 $\pm 1.00 \mathrm{GAE} 100$ $\mathrm{g}^{-1}$ dry weight of sample) and epicotyl $\left(308.93 \pm 3.77 \mathrm{GAE} 100 \mathrm{~g}^{-1}\right.$ dry weight of sample). A recent report has discussed the use of colorimetric methods in the screening of different sources of food phenolic antioxidants (Granato et al., 2018). A significant positive correlation existed between TPC and daidzein $(\mathrm{r}=0.9030, p=0.036)$ in the present study. However, no correlation existed between TPC and both total isoflavones and and genistein $(p>0.05)$ as evaluated

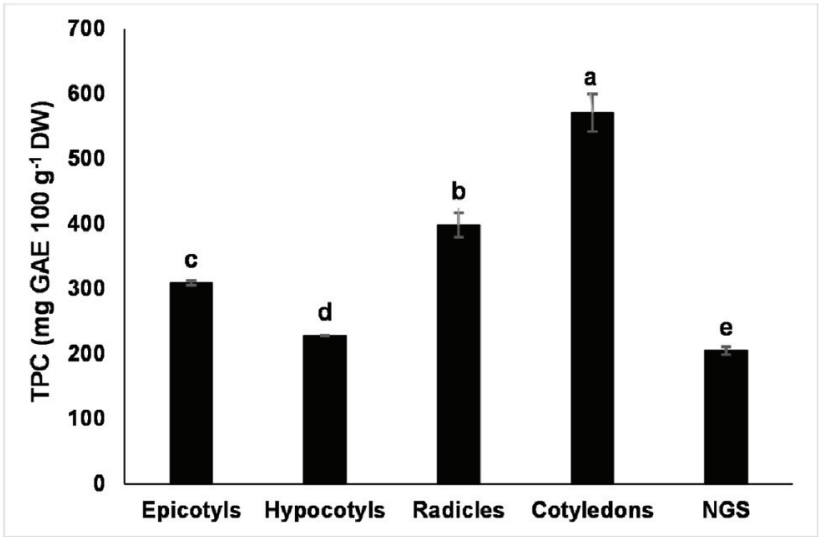

Figure 1. Total phenolic content (TPC) of non-germinated soybeans and samples germinated for $144 \mathrm{~h}$ at $35^{\circ} \mathrm{C}$ in the presence of light. Data represent mean values \pm standard deviation $(n=3)$. Values followed by the same letters are not significantly different $(p>0.05)$. Abbreviations: GAE, gallic acid equivalents; DW, dry weight; and NGS, non-germinated soybeans. 
Table 4. Radical scavenging activity ( $\mu \mathrm{mol} \mathrm{TE} \mathrm{g}^{-1} \mathrm{DW}$ ) of non-germinated soybeans and samples germinated for $144 \mathrm{~h}$ at $35^{\circ} \mathrm{C}$ in the presence of light

\begin{tabular}{llllll}
\hline \multirow{2}{*}{ Assay } & \multirow{2}{*}{ NGS } & \multicolumn{4}{c}{ Germinated soybean components } \\
\cline { 3 - 5 } & & Cotyledons & Epicotyls & Hypocotyls & Radicles \\
\hline DPPH & $289 \pm 1.0^{\mathrm{b}}$ & $324 \pm 19^{\mathrm{a}}$ & $266 \pm 10^{\mathrm{b}}$ & $110 \pm 80^{\mathrm{c}}$ & $278 \pm 50^{\mathrm{b}}$ \\
ABTS & $252 \pm 6.0^{\mathrm{d}}$ & $599 \pm 26^{\mathrm{a}}$ & $389 \pm 6.0^{\mathrm{b}}$ & $237 \pm 5.0^{\mathrm{d}}$ & $295 \pm 0.0^{\mathrm{c}}$ \\
\hline
\end{tabular}

Data represent mean values \pm standard deviation $(n=3)$. Values followed by the same letters within a row are not significantly different $(p>0.05)$. Abbreviations: TE, trolox equivalents; DW, dry weight; and NGS, non-germinated soybeans.

by HPLC. This suggests that the reaction taking place during the Folin-Ciocalteu assay is dependent on the structure of individual compounds. Furthermore, all germinated soybean components had a higher TPC compared to non-germinated soybeans $(204.73 \pm 5.08$ mg GAE $100 \mathrm{~g}^{-1}$ dry weight of sample). According to the data reported for several food legumes (Xu and Chang, 2007), the TPC of non-germinated soybeans was lower than that of lentils $(244.00$ mg GAE $100 \mathrm{~g}^{-1}$ ) and black beans (320.00 mg GAE $100 \mathrm{~g}^{-1}$ ) but it was higher than that of green peas (134.00 mg GAE $\left.100 \mathrm{~g}^{-1}\right)$ and chickpeas (154.00 mg GAE $100 \mathrm{~g}^{-1}$ ). However, except for black beans, all components of germinated soybeans showed higher TPC than the aforementioned legume seeds. Therefore, the results of this study suggest that the germination process may improve the TPC thus serving better as a source of phenolic compounds.

\subsection{Scavenging activity as affected by germination}

Free radicals may induce changes in DNA, oxidize LDL-cholesterol, inactivate enzymes, and cause cell damage, which are important biomarkers related to higher incidences of several chronic ailments (Amarowicz and Pegg, 2017; Fernandes et al., 2011; Peng et al., 2015; Perera et al., 2018). In food systems, oxidation caused by free radicals may induce sensory changes, decrease nutritional quality, including depletion of vitamins (e.g. vitamins $\mathrm{C}$ and $\mathrm{E}$ ) and affect polyunsaturated fatty acids (Ramírez-Cahero and Valdivia-López, 2018; Sartori et al., 2018; Shahidi and de Camargo, 2016). Bueno-Borges et al. (2017) carried out several antioxidant assays (e.g. ABTS, DPPH, ORAC, and Rancimat) and have suggested superior antioxidant properties of soybean isoflavones compared to that of tocopherols.

The antioxidant properties of food phenolics may be explained by single electron transfer (SET) or hydrogen atom transfer (HAT) (de Camargo et al, 2017; Leopoldini et al., 2004). While both electron and hydrogen transfer may be contemplated in DPPH assay, the ABTS assay is based on electron transfer reactions. Furthermore, ABTS is used to evaluate radical scavenging activity of both hydrophilic and lipophilic compounds. Hence, in the current study, both methods were used to evaluate the effects of germination in different soybeans components.

In general, germinated soybean components showed higher antiradical activity than non-germinated samples. In accordance to TPC results, the cotyledons exhibited the greatest ability in scavenging both radicals (Table 4). While cotyledons had 2.4-fold higher scavenging capacity towards ABTS radical cation, a lower difference was noted against DPPH radical (12\% higher) which may due to different mechanisms that are operative in each assay/reaction. A high positive correlation existed between the concentration of genistein ( $\mathrm{r}$ $=0.9088, p=0.033)$ and the ability of phenolic extracts in neutralizing the ABTS radical cation, which was not detected between total isoflavones and daidzein $(p>0.05)$ as evaluated by HPLC. These findings suggest the critical role of genistein as an antioxidant compound. In addition, no correlations were found between these aglycones and DPPH results. Therefore, considering the great difference for both assays and the lack of correlation between any aglycone and DPPH radical scavenging activity, it is possible to suggest that genistein may act through SET rather than via HAT.

\section{Conclusions}

Germination positively influenced the isoflavone profile of soybean. The cotyledons made the highest contribution to the total weight of the germinated soybean cotyledons. Hence, after germination for $144 \mathrm{~h}$, the cotyledons rendered a higher yield of aglycones (genistein and daidzein). Furthermore, only aglycones were detected in the radicles from $144 \mathrm{~h}$ until $168 \mathrm{~h}$ of germination, thus making this component a potential feedstock in developing functional ingredients and/or processing products as well as in future studies aiming at isolation, especially of daidzein, which was present in higher concentrations. Finally, this contribution lends support on the use of germination to improve the antioxidant potential of soybeans.

\section{Acknowledgments}

This work was partially funded by $\mathrm{CNPq} / \mathrm{MCT}$ and Fundação Araucária, Paraná state, Brazil. L.Y. Yoshiara would like to thank $\mathrm{CNPq}$ for her graduate scholarship. A. C. de Camargo is thankful to Coordination of Improvement of Higher Education-Ministry of Education of Brazil-CAPES for his postdoctoral fellowship. F. Shahidi thanks the Natural Science and Engineering Research Council (NSERC) of Canada for partial financial support. E.I. Ida is a CNPq Research Fellow.

\section{Conflict of interest}

The authors declare no conflict of interest.

\section{References}

Amarowicz, R., and Pegg, R.B. (2017). The potential protective effects of phenolic compounds against low-density lipoprotein oxidation. Curr. Pharm. Des. 23: 2754-2766.

Brand-Williams, W., Cuvelier, M.E., and Berset, C. (1995). Use of a free radical method to evaluate antioxidant activity. LWT-Food Sci. Technol. 28: 25-30.

Bueno-Borges, L.B., de Camargo, A.C., Sangaletti-Gerhard, N., Dos Santos, G.C.P., de Alencar, S.M., Shahidi, F., and Regitano-d'Arce, M.A.B. (2017). A highly stable soybean oil-rich miscella obtained by ethanolic extraction as a promising biodiesel feedstock. J. Am. Oil Chem. Soc. 94: 1101-1109.

Coward, L., Barnes, N.C., Setchell, K.D.R., and Barnes, S. (1993). Genistein, daidzein, and their beta-glycoside conjugates: antitumor isoflavones in soybean foods from American and Asian diets. J. Agric. Food 
Chem. 41: 1961-1967.

de Camargo, A.C., Regitano-d'Arce, M.A.B., Gallo, C.R., and Shahidi, F. (2015). Gamma-irradiation induced changes in microbiological status, phenolic profile and antioxidant activity of peanut skin. J. Funct. Foods 12: 129-143.

de Camargo, A.C., Regitano-d'Arce, M.A.B., and Shahidi, F. (2017). Phenolic profile of peanut by-products: antioxidant potential and inhibition of alpha-glucosidase and lipase activities. J. Am. Oil Chem. Soc. 94: 959971.

Falcão, H.G., Handa, C.L., Silva, M.B.R., de Camargo, A.C., Shahidi, F., Kurozawa, L.E., and Ida, E.I. (2018). Soybean ultrasound pre-treatment prior to soaking affects $\beta$-glucosidase activity, isoflavone profile and soaking time. Food Chem. 269: 404-412.

Fernandes, S.P., Dringen, R., Lawen, A., and Robinson, S.R. (2011). Inactivation of astrocytic glutamine synthetase by hydrogen peroxide requires iron. Neurosci. Lett. 490: 27-30.

Graham, T.L. (1991). Flavonoid and isoflavonoid distribution in developing soybean seedling tissues and in seed and root exudates. Plant Physiol. 95: 594-603.

Granato, D., Shahidi, F., Wrolstad, R., Kilmartin, P., Melton, L.D., Hidalgo, F.J., Miyashita, K., Camp, J.V., Alasalvar, C., Ismail, A.B., Elmore, S., Birch, G.G., Charalampopoulos, D., Astley, S.B., Pegg, R., Zhou, P., and Finglas, P. (2018). Antioxidant activity, total phenolics and flavonoids contents: Should we ban in vitro screening methods? Food Chem. 264: 471-475.

Hoeck, J.A., Fehr, W.R., Murphy, P.A., and Welke, G.A. (2000). Influence of genotype and environment on isoflavone contents of soybean. Crop Sci. 40: 48-51.

Ismael, B., and Hayes, K. (2005). $\beta$-Glycosidase activity toward different glycosidic forms of isoflavones. J. Agric. Food Chem. 53: 4918-4924.

Kim, S.-L., Lee, J.-E., Kwon, Y.-U., Kim, W.-H., Jung, G.-H., Kim, D.-W., Lee, C.-K., Lee, Y.Y., Kim, M.-J., Kim, Y.-H., Hwang, T.-Y., and Chung, I.-M. (2013). Introduction and nutritional evaluation of germinated soy germ. Food Chem. 136: 491-500.

Kudou, S., Fleury, Y., Welti, D., Magnolato, D., Uchida, T., Kitamura, K., and Okubo, K. (1991). Malonyl isoflavone glycosides in soybean seeds (Glycine max Merrill). Agric. Biol. Chem. 55: 2227-2233.

Lee, S.J., Ahn, J.K., Khanh, T.D., Chun, S.C., Kim, S.L., Ro, H.M., Song, H.K., and Chung, I.M. (2007). Comparison of isoflavone concentrations in soybean (Glycine max (L.) Merrill) sprouts grown under two different light conditions. J. Agric. Food Chem. 55: 9415-9421.

Leopoldini, M., Marino, T., Russo, N., and Toscano, M. (2004). Antioxidant properties of phenolic compounds: $\mathrm{H}$-atom versus electron transfer mechanism. J. Phys. Chem. 108: 4916-4922.

Lephart, E.D., West, T.W., Weber, K.S., Rhees, R.W., Setchell, K.D.R., Adlercreutz, H., and Lund, T.D. (2002). Neurobehavioral effects of dietary soy phytoestrogens. Neurotoxicol. Teratol. 24: 5-16.

Levis, S., Strickman-Stein, N., Doerge, D.R., and Krischer, J. (2010). Design and baseline characteristics of the soy phytoestrogens as replacement estrogen (SPARE) study - A clinical trial of the effects of soy isoflavones in menopausal women. Contemp. Clin. Trials. 31: 293-302.

Liggins, J., Bluck, L.J., Runswick, S., Atkinson, C., Coward, W.A., and Bingham, S.A. (2000). Daidzein and genistein contents of vegetables. Br. J. Nutr. 84: 717-725.

Liu, C., Li, S., Tsao, R., Li, S., and Zhang, Y. (2017). Extraction and isolation of potential anti-stroke compounds from black soybean (Glycine max L. Merrill) guided by in vitro PC12 cell model. J. Funct. Foods 31: 295-303.

Liu, Y.-J., Zhan, J., Liu, X.-L., Wang, Y., Ji, J., and He, Q.-Q. (2014). Dietary flavonoids intake and risk of type 2 diabetes: A meta-analysis of prospective cohort studies. Clin. Nutr. 33: 59-63.

Ma, W., Yuan, L., Yu, H., Ding, B., Xi, Y., Feng, J., and Xiao, R. (2010). Genistein as a neuroprotective antioxidant attenuates redox imbalance induced by $\beta$-amyloid peptides $25-35$ in PC12 cells. Int. J. Dev. Neurosci. 28: 289-295.

Martín-Cabrejas, M.A., Díaz, M.F., Aguilera, Y., Benítez, V., Mollá, E., and Esteban, R.M. (2008). Influence of germination on the soluble carbohydrates and dietary fibre fractions in non-conventional legumes. Food Chem. 107: 1045-1052.

Murugkar, D.A. (2015). Effect of different process parameters on the quality of soymilk and tofu from sprouted soybean. J. Food Sci. Technol.
52: 2886-2893.

Paucar-Menacho, L.M., Berhow, M.A., Mandarino, J.M.G., Chang, Y.K., and Mejia, E.G. (2010). Effect of time and temperature on bioactive compounds in germinated Brazilian soybean cultivar BRS 258. Food Res. Int. 43: 1856-1865.

Peng, H., Li, W., Li, H., Deng, Z., and Zhang, B. (2017). Extractable and nonextractable bound phenolic compositions and their antioxidant properties in seed coat and cotyledon of black soybean (Glycinemax (L.) Merr). J. Funct. Foods 32: 296-312.

Peng, S., Zhang, B., Yao, J., Duan, D., and Fang, J. (2015). Dual protection of hydroxytyrosol, an olive oil polyphenol, against oxidative damage in PC12 cells. Food Funct. 6: 2091-2100.

Perera, N., Ambigaipalan, P., and Shahidi, F. (2018). Epigallocatechin gallate (EGCG) esters with different chain lengths fatty acids and their antioxidant activity in food and biological systems. J. Food Bioact. 1: 124-133.

Quinhone Júnior, A., and Ida, E.I. (2015). Profile of the contents of different forms of soybean isoflavones and the effect of germination time on these compounds and the physical parameters in soybean sprouts. Food Chem. 166: 173-178.

Ramírez-Cahero, H.F., and Valdivia-López, M.A. (2018). Effect of gamma radiation on sugars and vitamin C: Radiolytic pathways. Food Chem. 245: 1131-1140.

Re, R., Pellegrini, N., Proteggente, A., Pannala, A., Yang, M., and Rice-Evans, C. (1999). Antioxidant activity applying an improved ABTS radical cation decolorization assay. Free Radic. Biol. Med. 26: 1231-1237.

Ribeiro, M.L.L., Mandarino, J.M.G., Carrão-Panizzi, M.C., Oliveira, M.C.N., Campo, C.B.H., Nepomuceno, A.L., and Ida, E.I. (2006). $\beta$-Glucosidase activity and isoflavone content in germinated soybean radicles and cotyledons. J. Food Biochem. 30: 453-465.

Rimbach, G., Boesch-Saadatmandi, C., Frank, J., Fuchs, D., Wenzel, U., Daniel, H., Hall, W.L., and Weinberg, P.D. (2008). Dietary isoflavones in the prevention of cardiovascular disease - A molecular perspective. Food Chem. Toxicol. 46: 1308-1319.

Sartori, A.G.O., Sampaio, G.R., Bastos, D.H.M., Regitano d'Arce, M.A.B., and Skibsted, L.H. (2018). Volatiles and tendency of radical formation of cold-pressed Brazil nut oil during ambient storage. J. Am. Oil Chem. Soc. 95: 721-730.

Shahidi, F., and de Camargo, A.C. (2016). Tocopherols and tocotrienols in common and emerging dietary sources: Occurrence, applications, and health benefits. Int. J. Mol. Sci. 17: 1745.

Shi, H., Nam, P.K., and Ma, Y. (2010). Comprehensive profiling of isoflavones, phytosterols, tocopherols, minerals, crude protein, lipid, and sugar during soybean (Glycine max) germination. J. Agric. Food Chem. 58: 4970-4976.

Swain, T., and Hillis, W.E. (1959). The phenolic constituents of Prunus domestica. I.-The quantitative analysis of phenolic constituents. J. Sci. Food Agric. 10: 63-68.

Xu, B.J., and Chang, S.K. (2007). A comparative study on phenolic profiles and antioxidant activities of legumes as affected by extraction solvents. J. Food Sci. 72: S159-S166.

Wanasundara, P.K.J.P.D., Wanasundara, U.N., and Shahidi, F. (1999). Changes in flax (Linum usitatissimum L.) seed lipids during germination. J. Am. Oil Chem. Soc. 76: 41-48.

Wang, S., Wang, Y., Pan, M.-H., and Ho, C.-T. (2017). Anti-obesity molecular mechanism of soy isoflavones: weaving the way to new therapeutic routes. Food Funct. 8: 3831-3846.

Yeo, J., and Shahidi, F. (2015). Critical evaluation of changes in the ratio of insoluble bound to soluble phenolics on antioxidant activity of lentils during germination. J. Agric. Food. Chem. 63: 379-381.

Yoshiara, L., Madeira, T., de Camargo, A., Shahidi, F., and Ida, E. (2018). Multistep optimization of $\beta$-glucosidase extraction from germinated soybeans (Glycine max L. Merril) and recovery of isoflavone aglycones. Foods 7: 7.

Yoshiara, L.Y., Madeira, T.B., Ribeiro, M.L.L., Mandarino, J.M.G., CarrãoPanizzi, M.C., and Ida, E.I. (2011). $\beta$-Glucosidase activity of soybean (Glycine max) embryonic axis germinated in the presence or absence of light. J. Food Biochem. 36: 699-705.

Yuan, J.P., Liu, Y.B., Peng, J., Wang, J.H., and Liu, X. (2009). Changes of isoflavone profile in the hypocotyls and cotyledons of soybeans during dry heating and germination. J. Agric. Food. Chem. 57: 9002-9010. 